\title{
O uso de coleções zoológicas como ferramenta didática
}

Este trabalho se propôs a revitalizar a Coleção Didática de Zoologia, realizando o registro de espécies de invertebrados terrestres e aquáticos da Caatinga, região do Vale do São Francisco, organizando, catalogando e disponibilizando material didático adequado para o ensino prático de disciplinas ligadas à área animal no curso de Engenharia Agronômica. A organização da uma Coleção Didática em Zoologia, servirá de instrumento para consulta dos alunos do ensino fundamental e médio da rede pública e privada do município de Juazeiro-BA, assim como subsidiar o ensino e pesquisa de graduandos e pós-graduandos da Universidade do Estado da Bahia (UNEB), Departamento de Tecnologia e Ciências Sociais (DTCS) Campus III.

Palavras-chave: Ciências Animais; Ensino; Aprendizagem.

\section{The use of zoological collections as a teaching tool}

This work aimed to revitalize the Didactic Collection of Zoology, registering species of terrestrial and aquatic invertebrates from the Caatinga, region of the São Francisco Valley, organizing, cataloging and making available suitable teaching material for the practical teaching of disciplines related to the animal area in the Agronomic Engineering course. The organization of a Didactic Collection of Zoology, will serve as an instrument for consultation of elementary and high school students from the public and private schools in the municipality of Juazeiro-BA, as well as subsidize the teaching and research of undergraduate and graduate students at the State University da Bahia (UNEB), Department of Technology and Social Sciences (DTCS) Campus III.

Keywords: Animal Sciences; Teaching; Learning.

Topic: Práticas, Didática e Metodologias do Ensino

Reviewed anonymously in the process of blind peer.
Received: $\mathbf{2 4 / 1 0 / 2 0 2 0}$

Approved: 25/01/2021
Alisson Ryan Alves da Silva (iD

Universidade do Estado da Bahia, Brasil

http://lattes.cnpq.br/4883587143870620

http://orcid.org/0000-0003-4596-0825

alissonryan150817@gmail.com

Carlos Alberto Batista Santos (iD)

Universidade do Estado da Bahia, Brasil

http://lattes.cnpq.br/0024544164324027

http://orcid.org/0000-0002-2049-5237

cabsantos@uneb.br
Referencing this:

SILVA, A. R. A.; SANTOS, C. A. B.. O uso de coleções zoológicas como ferramenta didática. Educationis, v.9, n.1, p.53-57, 2021. DOI: http://doi.org/10.6008/CBPC2318-3047.2021.001.0007 


\section{INTRODUÇÃO}

As coleções zoológicas são de grande importância para o aprendizado de alunos tanto do ensino superior quanto do ensino médio e constituem acervos importantes para o entendimento e estudo da biodiversidade (BEHRENS, 2000).

O ensino por meio das coleções pode permitir que os alunos aprimorem a aprendizagem, pois a ilustração dos animais (por meio de imagens) no ensino não consegue demonstrar a realidade que cada espécie possui (SANTOS et al., 2011).

O Laboratório de Ciências Animais da UNEB/DTCS Campus III, abriga um acervo de insetos utilizados para fins didáticos (Figura 1) que apresenta, atualmente, uma grande diversidade zoológica. Os animais estão organizados taxonômicamente de acordo com a ordem, em estantes (KURY et al., 2006), no entanto, faz-se necessário uma organização mais detalhada. Cada indivíduo deverá ter um número de identificação. Organizar o material da coleção didática, armazenada em álcool 70\%; ou a seco.

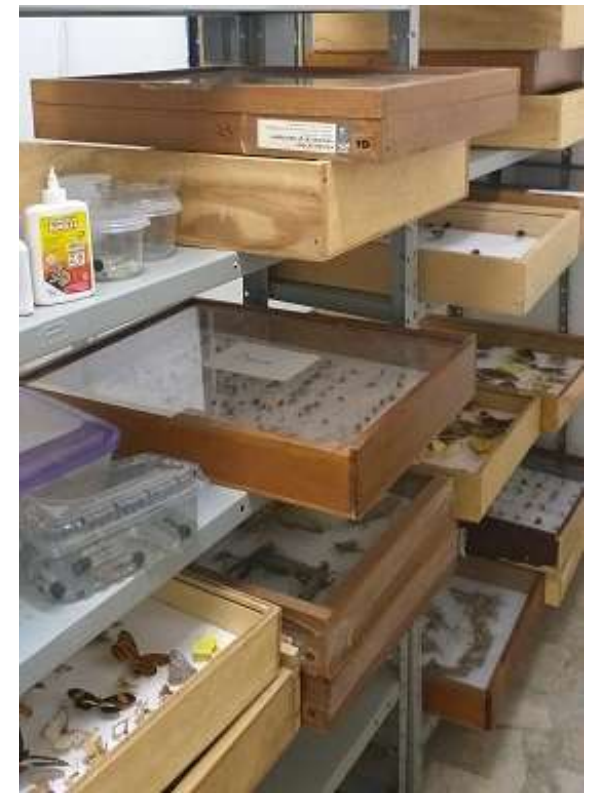

Figura 1: Sala do acervo entomológico, Laboratório de Ciências Animais - UNEB/DTCS III.

O material da coleção didática é utilizado, prioritariamente, durante as aulas práticas pelos acadêmicos da graduação e pós-graduação.

Os laboratórios de coleções zoológicas, contém materiais de valor inestimável que também servem de testemunhos da biodiversidade e como base para diversos estudos futuros (CHIVIAN, 2002).

Tendo em vista todas essas considerações foi proposto neste estudo a organização, manutenção e incremento da coleção (Figura 2), para auxiliar no planejamento e aplicação de atividades didáticas envolvendo alunos nas disciplinas de Ciências Animais, além do atendimento a estudantes do Ensino Médio e Técnico da rede pública do município de Juazeiro, Bahia.

As Coleções Didáticas possibilitam a inserção de estudantes no desenvolvimento de projetos de iniciação científica, mestrado e doutorado, bem como o desenvolvimento de ações sob a forma de atividades complementares de diversos trabalhos, sistematicamente organizados como coletas, cursos de preparação 
de material zoológico, subsidiando também visitas monitoradas à coleção por alunos da rede pública (ZAHER et al., 2003; MARTINS, 2000).

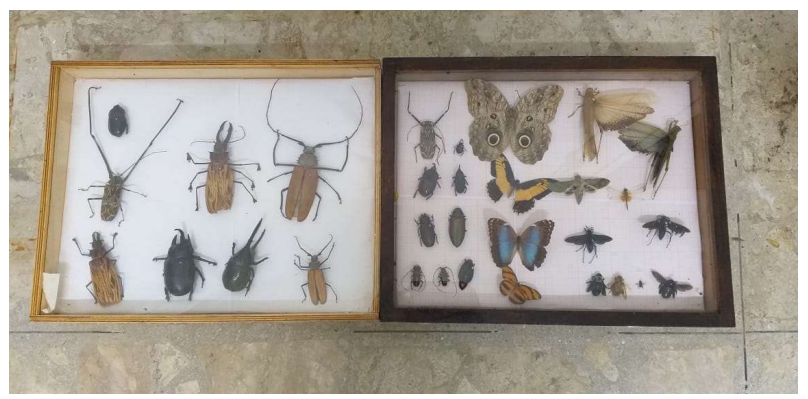

Figura 2: Caixas entomológicas acervo entomológico, Laboratório de Ciências Animais - UNEB/DTCS III.

Profissionais especializados são necessários à identificação dos diversos grupos animais, lançando mão da utilização de chaves dicotômicas, manuais práticos e pranchas de desenhos (MARTINS, 1994), essa especificidade oportuniza o estabelecimento com outras Instituições de Ensino Superior e Profissionais de diversas áreas, promovendo uma rede de estudo e pesquisa na área de Ciências Animais, Ecologia e Biodiversidade entre outras.

No entanto, o maior ganho para a sociedade que visualizamos será a possibilidade de estreitar laços com a rede pública de ensino estadual, uma rede de solidariedade, que contribuirá com a formação dos alunos da rede de ensino básico, futuros acadêmicos das Instituições de Ensino Superior na região do vale do São Francisco.

O Laboratório de Ciências Animais da UNEB/DTCS Campus III, abriga um acervo de insetos utilizados para fins didáticos que apresenta, atualmente, uma grande diversidade zoológica. Os animais estão organizados taxonômicamente de acordo com a ordem, em estantes (FIGURA 1) (KURY et al., 2006). Esse trabalho teve como objetivo, proporcionar aos discentes de Agronomia e das escolas públicas de ensino médio de Juazeiro/BA, uma experiência de ensino e aprendizagem em Ciências Animais.

\section{MATERIAIS E MÉTODOS}

O Laboratório de Ciências Animais da Universidade do Estado da Bahia, Departamento de Tecnologia e Ciências Sociais, campus III é prioritariamente usado para o desenvolvimento e elaboração de aulas práticas para algumas disciplinas do curso de Engenharia Agronômica, para atividades de pesquisa dos mestrados acadêmicos para atividades de visitas monitoradas à coleção por alunos da rede pública, atividades importantes para valorização e utilização de coleções zoológicas (PINTO, 1999). Para realização desse estudo, os docentes e técnicos laboratoriais envolvidos nessas atividades foram contatados e suas atividades planejadas com antecedência.

O material didático preexistente foi etiquetado com um número de registro, catalogado em arquivo digital. Quanto à conservação da coleção, a maior parte dos animais, especialmente os invertebrados, são conservadas a seco. No caso dos animais armazenados em álcool $70 \%$, foi feita a substituição da solução conservante, este processo deverá ser mantido a cada doze meses, para impedir que os exemplares 
apodreçam, mantendo-os conservados.

Nas estantes e caixas entomológicas foi colocado naftalina, que forma uma fase gasosa repelente para manter a conservação do material, impedindo a entrada de insetos invasores. Com o tempo a naftalina sofre o processo de sublimação até desaparecer por completo, dessa forma, a cada trinta dias far-se-á a revisão de toda a coleção avaliando a integridade do material e substituindo a naftalina quando necessário.

Utilizou-se de chaves dicotômicas, manuais práticos e pranchas de desenhos e consulta a especialistas quando necessário (MARICATO et al., 2007), para a identificação dos diversos grupos animais, sua preparação e melhor forma de conservação.

Muitos animais chegam ao laboratório por doação (Figura 3) ou como material obtido durante o desenvolvimento de projetos de Iniciação Científica. Cada vez que exemplares novos chegam à coleção didática, é realizada a identificação e o tombamento do material, junto os dados do animal, tais como nome científico e popular da espécie, data e local da coleta e coletor, registrados de forma digital (GALVÃO, 2011; THIENGO, 2011).

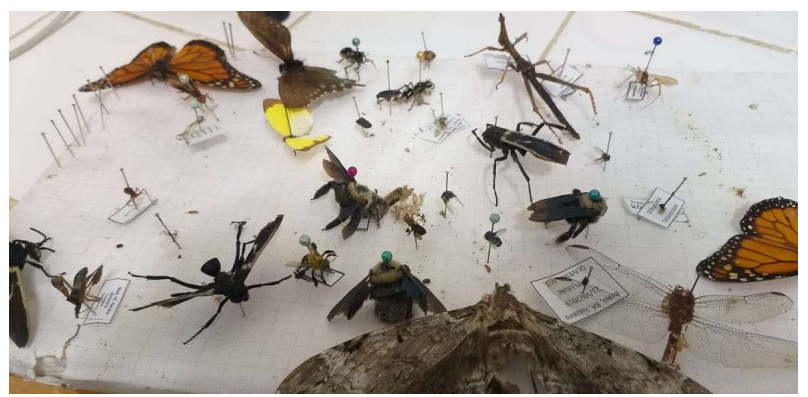

Figura 3: Insetos doados pelos alunos da graduação durante aulas práticas (UNEB/DTCS III).

\section{RESULTADOS E DISCUSSÃO}

Através deste trabalho, foi possível atendermos melhor as demandas dos cursos de graduação da UNEB/DTCS Campus III que usam as dependências do Laboratório de Ciências Animais., organizando a coleção zoológica didática, apoiando os estudantes que desenvolvem projetos de iniciação científica que se relacionem com a área zoológica, promovendo uma melhor conservação e manutenção do material didático.

Com a inclusão do Bolsista Júnior CNPq, foi possível dar maior apoio aos estudantes que desenvolvem projetos de Iniciação Científica que se relacionam com a área zoológica. Promoveu-se uma melhor conservação e manutenção do material didático.

\section{CONCLUSÕES}

A partir da inserção do Bolsista Júnior CNPq na iniciação científica, tivemos a comprovação da contribuição social da Universidade do Estado da Bahia, que a partir das atividades teve a possibilidade de estreitar laços com a rede pública de ensino estadual e contribuir com a formação do educando, assim como a inserção deste na dinâmica de produção do conhecimento através da publicação de artigos que se encontram em fase de construção, e socialização das experiências vivenciadas. 
AGRADECIMENTOS: À Universidade do Estado da Bahia (UNEB), Departamento de Tecnologia e Ciências

Sociais (DTCS), campus III. Ao CNPq/IC JÚNIOR, pela bolsa de incentivo à pesquisa.

\section{REFERÊNCIAS}

BEHRENS, M. A.. O paradigma emergente e a prática pedagógica. 2 ed. Curitiba, 2000.

CHIVIAN, E.. Biodiversity: its importance to human health. Interim Executive Summary. Center for health and the Global Environment, Havard Medical School Champagnat, 2002.

GALVÃO, C.. Curso de pós-graduação em Biodiversidade e Saúde do Instituto Oswaldo Cruz: ampliando a missão da Fiocruz. In: SEMINÁRIO SOBRE GESTÃO E CURADORIA DE COLEÇÕES ZOOLÓGICAS DA FIOCRUZ, 1. Anais. Rio de Janeiro, 2011.

KURY, A. B.; ALEIXO, A.; BONALDO, A. B.. Diretrizes e estratégias para a modernização de coleções biológicas brasileiras e a consolidação de sistemas integrados de informação sobre biodiversidade. Brasília: Centro de Gestão e Estudos Estratégicos: MCT, 2006.

MARICATO, H. S.; OLIVEIRA, W. D.; BORGES, M. F. DINIZ, J. L. M.. A utilização da prática em zoologia através de coleções didáticas: um recurso para a construção dos 7160 conhecimentos dos alunos no ensino Médio do município de Jataí - Goiás. In: CONGRESSO DE EDUCAÇÃO DO SUDOESTE GOIANO, 23. Anais. Universidade Federal de Goiás, 2007.
MARTINS, U. A.. Coleção taxonômica. In: PAPAVERO, N.. Fundamentos práticos de taxonomia zoológica: coleções, bibliografia, nomenclatura. 2 ed. São Paulo: UNESP-FAPESP, 1994.

MARTINS, P. L. O.. Didática teórica/Didática prática. Para além do confronto. 6 ed. São Paulo: Loyola, 2000.

PINTO, J. M. S.; LOPES, S. A.. Importância dos museus no ensino básico e secundário. Comunicar Ciência, v.1, n.3, 1999.

SANTOS, D. C. J.; SOUTO, L. S.. Coleção entomológica como ferramenta facilitadora para a aprendizagem de Ciências no ensino fundamental. Scientia Plena, v.7, n.5, p.1-8, 2011.

THIENGO, S. C.. Biodiversidade e saúde pública. In: SEMINÁRIO SOBRE GESTÃO E CURADORIA DE COLEÇÕES ZOOLÓGICAS DA FIOCRUZ, 1. Anais. Rio de Janeiro: Corbã, 2011.

ZAHER, H.; YOUNG, P. S.. As coleções zoológicas brasileiras: panorama e desafios. Ciência e Cultura, São Paulo, v.55, n.3, p.24-26, 2003.

A CBPC - Companhia Brasileira de Produção Científica (CNPJ: 11.221.422/0001-03) detém os direitos materiais desta publicação. Os direitos referem-se à publicação do trabalho em qualquer parte do mundo, incluindo os direitos às renovações, expansões e disseminações da contribuição, bem como outros direitos subsidiários. Todos os trabalhos publicados eletronicamente poderão posteriormente ser publicados em coletâneas impressas sob coordenação da Sustenere Publishing, da Companhia Brasileira de Produção Científica e seus parceiros autorizados. Os (as) autores (as) preservam os direitos autorais, mas não têm permissão para a publicação da contribuição em outro meio, impresso ou digital, em português ou em tradução. 